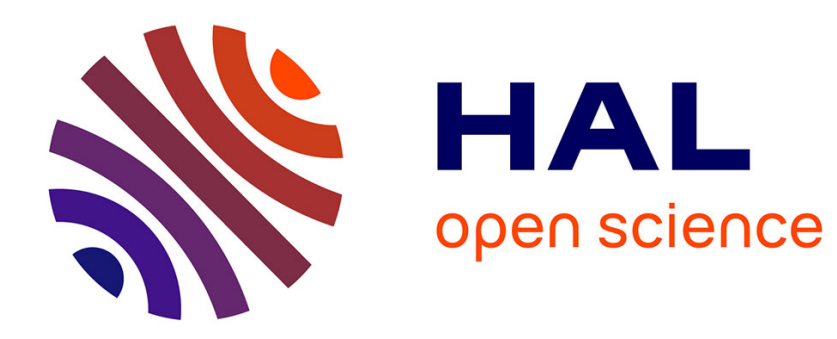

\title{
Second language acquisition of Italian accusative and dative clitics
}

Maurizio Santoro

\section{To cite this version:}

Maurizio Santoro. Second language acquisition of Italian accusative and dative clitics. Second Language Research, 2007, 23 (1), pp.37-50. 10.1177/0267658307071603 . hal-00570722

\section{HAL Id: hal-00570722 \\ https://hal.science/hal-00570722}

Submitted on 1 Mar 2011

HAL is a multi-disciplinary open access archive for the deposit and dissemination of scientific research documents, whether they are published or not. The documents may come from teaching and research institutions in France or abroad, or from public or private research centers.
L'archive ouverte pluridisciplinaire HAL, est destinée au dépôt et à la diffusion de documents scientifiques de niveau recherche, publiés ou non, émanant des établissements d'enseignement et de recherche français ou étrangers, des laboratoires publics ou privés. 


\title{
Second language acquisition of Italian accusative and dative clitics
}

\author{
Maurizio Santoro Queensborough Community College, \\ City University of New York
}

This experimental study investigates the acquisition of Italian accusative and dative clitics by English adult speakers. These pronouns are non-existent in English. Results from a grammaticality judgement task show that Italian accusative and dative clitics develop slowly but gradually in Italian second language (L2) grammars. Interestingly, the placement properties appear to develop earlier than their case properties. The possible implications of these findings for theories of the L2 initial state are considered.

\section{Introduction}

Although recent studies of the acquisition of Romance clitics by second language (L2) learners (see, amongst others Bruhn-Garavito and Montrul, 1996; White, 1996; Duffield and White, 1999; Duffield et al., 2002) have reported a delay in the use of clitics in a target-like way, there has been no investigation of how knowledge of clitic placement and knowledge of clitic case properties interact. The present study provides evidence of English speakers' knowledge of the distribution and case-marking properties of Italian non-subject clitics, where proficiency ranged from beginner through intermediate to advanced.

\section{English and Italian pronominal systems}

According to Cardinaletti and Starke (1999), Italian has basically two categories of pronouns. Some behave like full DPs, while others display special syntactic properties. The former are strong pronouns, and the

Address for correspondence: Maurizio Santoro, Foreign Language and Literature Department, Queensborough Community College of the City University of New York, 222-05 56th Avenue, Bayside, New York, NY 11364, USA; email: MASantoro@qcc.cuny.edu 
latter are clitics. Italian strong object pronouns - me (me), te (you), lui (him), lei (her), noi (us) voi (you plural), loro (them) - usually occur in post-verbal position, just like full DPs. The accusative clitics corresponding to the strong forms are: $m i, t i, l o, l a, c i, v i, l i, l e$, while the dative clitics are: $m i, t i, g l i, l e, c i, v i$, gli/loro. Neither accusative nor dative clitics pattern with DPs. They appear pre-verbally in simple tensed clauses. This position cannot be occupied by a strong pronoun, as shown in (1):

1) Maria *lei/la chiama. (amica)

Maria HER/her ${ }_{\text {acc }}$ call-PRES (friend)

'Maria is calling her.'

The sequence clitic + verb, or verb + clitic in imperative or non-finite clauses, cannot be interrupted by any element, except another clitic. Strong pronouns, on the other hand, can be separated from their selecting verb. This contrast is illustrated in (2):
2) a. *Maria la solo chiama Maria her ${ }_{\text {acc }}$ only call-PRES
'Maria is calling only her.'
b. Maria chiama solo lei Maria call-PRES only HER 'Maria is calling only HER.'

Furthermore, clitics cannot be coordinated, or contrastively stressed:
3) *Maria lo e la chiama. Maria $\operatorname{him}_{\text {acc }}$ and her acc $_{\text {call-PRES }}$ 'Maria is calling him and her.'
4) *Maria la chiama. (Luisa, non Mario) Maria her $_{\text {acc }}$ call-PRES (Luisa, not Mario) 'Maria is calling her.' (Luisa not Mario)

By contrast, strong pronouns can be conjoined, or contrastively stressed:

5) Maria chiama lei e lui. Maria call-PRES HER and HIM 'Maria is calling HER and HIM.'

6) Maria chiama lei non lui. Maria call-PRES HER not HIM 'Maria is calling HER not HIM.'

To account for these contrasts, Sportiche (1996) has proposed that clitics are generated as the heads of clitic 'voices'. These are functional categories located above the $\mathrm{vP}$, and are licensed by pro constituents in relevant theta positions in the clause. These pro constituents move to 
the specifier of the clitic voice at LF. Furthermore, accusative and dative voices are distinct projections.

English does not have clitics, but rather strong and weak forms of pronouns. Although strong and weak pronouns have different distributions, as illustrated in (7) (examples from Cardinaletti and Starke, 1999: 210), weak pronouns are different from clitics. In particular they can occur as the objects of prepositions (see (8)) which is impossible for clitics:

7) Strong form

John saw him

John saw only him

John saw him and Mary

John saw him not Mary

8) I am listening tó 'm.

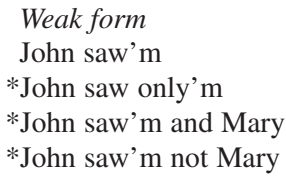

In addition, pronouns in English are not distinguished morphologically for accusative and dative case.

\section{Hypotheses}

Assuming Sportiche's (1996) analysis of clitics, the task facing English speakers learning Italian is not only to acquire new functional categories (the clitic 'voices') absent in the first language (L1), but also to determine the morphological contrast between accusative and dative. How do they develop such knowledge? Current second language acquisition research offers different hypotheses about how functional structure develops in L2 grammars. Three are considered in this study. According to the Minimal Trees hypothesis (Vainikka and Young-Scholten, 1994; 1996) early L2 grammars do not show any functional categories. Initially, they project only lexical categories (VP, NP, PP, AP). Functional projections emerge gradually from interaction with input, and initially may be underspecified. In the case of Italian clitics, this proposal predicts that beginning learners would not use, or even recognize, them in L2 input. When the clitic voices emerge, they may initially be underspecified for case properties.

The Full Access hypothesis (see e.g., Epstein et al., 1996), on the other hand, assumes an initial fully developed functional structure. All principles and properties available to child L1 learners are also available to adult L2 learners. Functional categories not instantiated in the L1 should be activated quickly by L2 input. This hypothesis, contrary 
to the previous one, predicts an early presence of clitic voices in L2 grammars. Beginners should be able to recognize them in L2 input, and use them with some degree of accuracy. Acquisition of all their properties could, however, be slowed down by interference from operations involved in the cliticization process. For instance, Sportiche's (1996) analysis assumes that pro movement to the specifier of a clitic voice is A-bar movement. Various first and second language acquisition studies have reported that syntactic operations involving A-bar movements are quite difficult to acquire (on the L1 acquisition of scrambling in Dutch, see Schaeffer, 1997; on the L2 acquisition of wh-movement in German and English, see, respectively, Vainikka and Young Scholten, 1994; King, 2000). In other words, acquisition delays involving Italian clitics may be due to general difficulties L2 learners have in dealing with A-bar movements, rather than to the inaccessibility of knowledge of functional structure.

Finally, Bley-Vroman (1989) and Clahsen and Muysken (1996) among others have proposed that the universal linguistic knowledge that guides first language acquisition is not available to L2 learners (the No Access hypothesis). Because of this deficiency, they use cognitive learning mechanisms that are not strictly linguistic. Bley-Vroman (1989), for instance, suggests that L2 learners use general problem-solving processes, which include analysis, analogy, hypothesis formation and testing as well as their L1 knowledge. Their core linguistic knowledge derives from the ability to analogize from the L1 to the L2. Aspects of the L2 that are not present in learners' L1 may be particularly problematic to acquire due to the lack of clear similarities between the native and the target language. This proposal predicts that the acquisition of Italian clitics might be a long and variable process. Even where clitics are acquired, morphological and placement inaccuracies may persist.

The ability of each of the above hypotheses to explain the results of the experiment reported in the next section will be discussed in Section V.

\section{The experiment}

\section{Participants}

Forty-eight participants took part in the experiment; 36 of them were adult native English speakers studying Italian in various New York City 
colleges. Their age ranged from 18 to 30 years. They were divided into three groups according to the number of Italian classes attended and the amount of instruction received: beginner $(n=12)$, intermediate $(n=12)$ and advanced $(n=12)$. The beginner group had completed one year of instruction, the intermediate group two years, and the advanced group had received Italian instruction for an extensive period of time. Twelve university-educated monolingual Italian speakers (age range 18-35) served as a control group.

\section{Materials}

The test instrument used was a grammaticality judgement task (GJT). This type of instrument has also been employed in previous studies to test L2 speakers' knowledge of clitic properties (e.g. Montrul, 1996; Duffield and White, 1999). Participants read a stimulus sentence on a computer screen and had to determine whether the sentence was grammatical or ungrammatical by pressing the appropriate button. A new stimulus sentence was presented every 30 seconds. At the end of this time, the sentence would disappear. The aim was to ensure that responses reflected participants' initial reactions. The test items comprised 5 sentence-types involving clitics in different structural positions (see Table 1), marked for accusative and dative case (see Tables 2 and 3).

The cl- $\mathrm{V}_{\text {fin }}$ and cl-AUX $\mathrm{V}_{\mathrm{pp}}$ sentence-types involved clitics in finite clauses with or without auxiliary verbs. In each group of stimuli there were 4 tokens of grammatically-placed and 4 tokens of ungrammatically-placed pronouns. For each sentence-type there were also 8

Table 1 Samples of grammatical and ungrammatical stimuli testing for placement

\begin{tabular}{|c|c|}
\hline Sentence-type & Sentence \\
\hline $\mathrm{Cl}-\mathrm{V}_{\text {fin }}$ & $\begin{array}{l}\text { Quando vedrá la sua ragazza, Marco la bacerá con affetto. } \\
\text { * II gelato, gli americani mangiano lo sempre con piacere. }\end{array}$ \\
\hline & $\begin{array}{l}\text { * Luelle signore, tutti le hanno ammirate per la loro eleganza. } \\
\text { * signora Casali, sua figlia ha riconosciuta la immediatamente. }\end{array}$ \\
\hline cl-MOD-V $\mathrm{inf}_{\mathrm{n}}$ & $\begin{array}{l}\text { Le verdure, i bambini le devono mangiare spesso. } \\
\text { * Quando i bambini ricevono dei regali, vogliono li aprire subito. }\end{array}$ \\
\hline cl-CAUS- $V_{\text {inf }}$ & $\begin{array}{l}\text { Poiché Marco ha una bella voce, gli amici lo fanno cantare per ore. } \\
\text { * II professore, gli studenti fanno lo sempre arrabbiare. }\end{array}$ \\
\hline$A U X-c l-V_{p p}$ & $\begin{array}{l}\text { Dopo averle cantate, le canzoni sembravano più interessanti. } \\
\text { * Le amiche, Maria era felice di le aver invitate. }\end{array}$ \\
\hline
\end{tabular}


Table 2 Samples of grammatical and ungrammatical items testing for accusative case

\begin{tabular}{|c|c|}
\hline Sentence-type & Items \\
\hline $\mathrm{cl}-\mathrm{V}_{\text {fin }}$ & Le partite di calcio, gli italiani le guardano ogni domenica. \\
\hline cl-AUX V $v_{p p}$ & $\begin{array}{l}\text { * Poiché Marcello non aveva soldi, Luigi gli ha prestato } 100 \text { dollari. } \\
\text { Quando Claudia ha incontrato il suo amico, I'ha detto grazie }\end{array}$ \\
\hline cl-MOD-V ${ }_{\text {inf }}$ & $\begin{array}{l}\text { Gli amici, Piero li vuole invitare alla festa di compleanno. } \\
\text { * Marcello incontrerà la sua ragazza stasera perché la vuole parlare. }\end{array}$ \\
\hline cl-CAUS- $V_{\text {inf }}$ & $\begin{array}{l}\text { Povero Carlo! II suo capo lo fa lavorare molto. } \\
\text { * Povera Maria! I genitori la fanno sempre pulire la stanza. }\end{array}$ \\
\hline$A \cup X-c l-V_{p p}$ & $\begin{array}{l}\text { Dopo averlo superato, il corso sembrava meno difficile. } \\
\text { * Dopo averla parlato, Maria ha capito finalmente la situazione. }\end{array}$ \\
\hline
\end{tabular}

Table 3 Samples of grammatical and ungrammatical items testing for dative case

\begin{tabular}{|c|c|}
\hline Sentence-type & Items \\
\hline $\mathrm{cl}-\mathrm{V}_{\text {fin }}$ & Quando Marta parla con sua mamma, le dice sempre la verità. \\
\hline$c l-A U X V_{p p}$ & $\begin{array}{l}\text { Poiché Marcello non aveva soldi, Luigi gli ha prestato } 100 \text { dollari. } \\
\text { * Mario ha visto la signora Ansani e le ha salutata. }\end{array}$ \\
\hline cl-MOD-V $V_{\text {inf }}$ & $\begin{array}{l}\text { Suo figlio, il papà non gli vuole prestare la macchina. } \\
\text { * La musica classica, i giovani le devono ascoltare di più. }\end{array}$ \\
\hline cl-CAUS- $V_{\text {inf }}$ & $\begin{array}{l}\text { I professori di Marta sono molto severi. Le fanno sempre } \\
\text { leggere molti libri. }\end{array}$ \\
\hline$A U X-c l-V_{p p}$ & $\begin{array}{l}\text { Dopo averle parlato, Carla si è calmata. } \\
\text { * L'italiano, Joan era contenta di avergli imparato. }\end{array}$ \\
\hline
\end{tabular}

grammatical and 8 ungrammatical tokens testing for accusative or dative case. The ungrammatical sentences featured pronouns occurring with verbs that do not select them.

The cl-MOD- $\mathrm{V}_{\text {inf }}$ sentence-type involved the use of clitics with modal or other restructuring verbs. The task presented only pronouns placed in preverbal position, even though they can also appear after the infinitive. Sentences with post-infinitival clitics were excluded in order to maintain a certain experimental consistency. In total, there were 4 tokens of grammatically-placed pronouns before the modal verb, and 4 ungrammatical tokens where the pronoun appeared between the modal and the infinitival verb. There were also 8 grammatical and 8 ungrammatical sentences testing for accusative or dative case. The cl-CAUS- $\mathrm{V}_{\text {inf }}$ sentence-type involved the use of clitics in causative structures. Most of the sentences presented the Italian causative verb fare ('make, get'). Four grammatical tokens showed the pronoun before 
the causative, whereas their ungrammatical counterparts had the clitic placed between the causative and the main verb. Sixteen additional sentences (8 grammatical and 8 ungrammatical) featured accusative and dative appearing with correct or incorrect selecting verbs.

The AUX-cl- $\mathrm{V}_{\mathrm{pp}}$ sentence-type tested for clitic placement and casemarking in non-finite clauses featuring an auxiliary verb. The 8 tokens testing for placement presented 4 grammatical items with the pronoun placed between the auxiliary verb and the participle, and 4 ungrammatical items with the clitic placed before the auxiliary verb. In addition there were 8 tokens (4 grammatical and 4 ungrammatical) testing for accusative case, and 8 tokens ( 4 grammatical and 4 ungrammatical) testing for dative case. This sentence-type was incorporated to investigate whether the nature of the auxiliary verb (finite vs. non-finite) would be influential on the acquisition of the pronouns.

In addition to the 120 test-items, a set of 48 sentences ( 24 grammatical and 24 ungrammatical) functioned as distracters, giving a total of 168 stimuli. All sentences were lexically and semantically controlled in order to avoid possible misinterpretations. They were also systematically randomized.

\section{Procedure}

Prior to the administration of the test, participants were trained on the modalities of the experiment, and completed a practice session. In addition, they were presented with a list of Italian terms that might be unfamiliar, translated into English. Participants took on average 40-45 minutes to complete the entire task. The control group followed the same training procedure as the other participants and completed the task in 25-30 minutes.

\section{Results}

Responses to test sentences were coded as 'correct' or 'incorrect', based on the expected grammaticality or ungrammaticality of a given stimulus item. Accuracy rates were then computed. Table 4 shows the accuracy of each group on the placement and case-marking of clitics. Data show that beginners and intermediates were more accurate with grammatical items than with their ungrammatical counterparts. The differences between the 


\section{Italian accusative and dative clitics}

Table 4 Accuracy rates on grammatical and ungrammatical items testing for placement, accusative care and dative case of the three experimental groups and Italian natives

\begin{tabular}{lll}
\hline Property & $\begin{array}{l}\text { Grammatical }(k=240) \\
\text { percentage accurate }\end{array}$ & $\begin{array}{l}\text { Ungrammatical }(k=240) \\
\text { percentage accurate }\end{array}$ \\
\hline $\begin{array}{l}\text { Beginner: } \\
\text { Placement }\end{array}$ & 77 & \\
Case (accusative) & 74 & 54 \\
Case (dative) & 77 & 40 \\
Intermediate: & & \\
Placement & 82 & 69 \\
Case (accusative) & 74 & 28 \\
Case (dative) & 72 & 48 \\
Advanced: & & \\
Placement & 80 & 86 \\
Case (accusative) & 84 & 42 \\
Case (dative) & 67 & 70 \\
Native: & & \\
Placement & 92 & 98 \\
Case (accusative) & 92 & 96 \\
Case (dative) & 93 & 92 \\
\hline
\end{tabular}

two groups are statistically significant for all the properties tested (see Table 5). Such discrepancies, however, become less visible at the advanced level, and totally disappear with Italian controls.

This profile of results indicates that L2 learners, contrary to the native speakers, differ in their treatment of ungrammatical and grammatical test sentences. As we have seen, it is with the former type of

Table 5 Comparison of accuracy on grammatical and ungrammatical tokens of the three manipulation types across the three experimental groups and the Italian natives

\begin{tabular}{lll}
\hline Placement & Accusative & Dative \\
\hline Beginners: & & \\
$T_{1}(22)=2.39, p<0.05^{*}$ & $T_{1}(22)=6.18, p<0.001^{* * *}$ & $T_{1}(22)=4.63, p<0.001^{* * *}$ \\
$T_{2}(18)=8.34, p<001^{* * *}$ & $T_{2}(18)=5000, p<001^{* * *}$ & $T_{2}(18)=5000, p<001^{* * *}$ \\
Intermediate: & & \\
$T_{1}(22)=1.66, p<1$ & $T_{1}(18)=7.15, p<0.001^{* * *}$ & $T_{1}(18)=2.75, p<0.05^{*}$ \\
$T_{2}(18)=2.61<05^{*}$ & $T_{2}(18)=5000, p<001^{* * *}$ & $T_{2}(18)=5.36, p<0.001^{* * *}$ \\
Advanced: & & \\
$T_{1}<1$ & $T_{1}(18)=0.89, p<0.001^{* * *}$ & $T_{1}<1$ \\
$T_{2}<1$ & $T_{2}(18)=5000, p<0.001^{* * *}$ & $T_{2}<1$ \\
Native: & & \\
$T_{1}<1$ & $T_{1}<1$ & $T_{1}<1$ \\
$T_{2}<1$ & $T_{2}<1$ & $T_{2}<1$ \\
\hline
\end{tabular}

Notes: * indicates degree of significance; $T_{1}$ indicates subject-based analysis of variance; $T_{2}$ indicates item-based analysis of variance. 
stimuli that the lower accuracy rates are reported. Such 'false positives' (responses that an ungrammatical item is grammatical) may suggest that English speakers - even those in the advanced group - have internalized grammars that permit these constructions.

From an acquisition perspective, this means that, first of all, mastering the correct use of Italian accusative and dative pronouns is quite problematic. After two years of instruction, English speakers have not yet gained full control of these pronouns. They are still quite uncertain on how to correctly place them in the structure, or how to associate them with the appropriate selecting verb.

In any event, despite their difficulties, L2 learners tend to visibly improve the use of Italian pronouns, as they become more proficient in the language. Figure 1 shows, in fact, that there is a gradual increase in accuracy, especially with the ungrammatical items. As can be seen, the intermediate group responded to ungrammatical items testing for Placement with greater accuracy than the beginners' group. The difference of the two means (54\% vs. 69\%) is, in fact, statistically significant $\left(t_{1}(22)=1.44, p<.05 ; t_{2}(18)=3.55, p<.05\right)$. The same cannot be said with the items testing for Accusative or Dative Case where learners' improvement was weak $\left(t_{1}<1 ; t_{2}<1\right)$.

The advanced level is characterized by a general jump toward nativelike performance. Ungrammatical test-items are judged with greater accuracy as compared to the intermediate group. Discrepancies among the two groups, in fact, are statistically significant for all three manipulation types (Placement: $t_{1}(22)=69.6, p<.05 ; t_{2}(18)=4.14$,

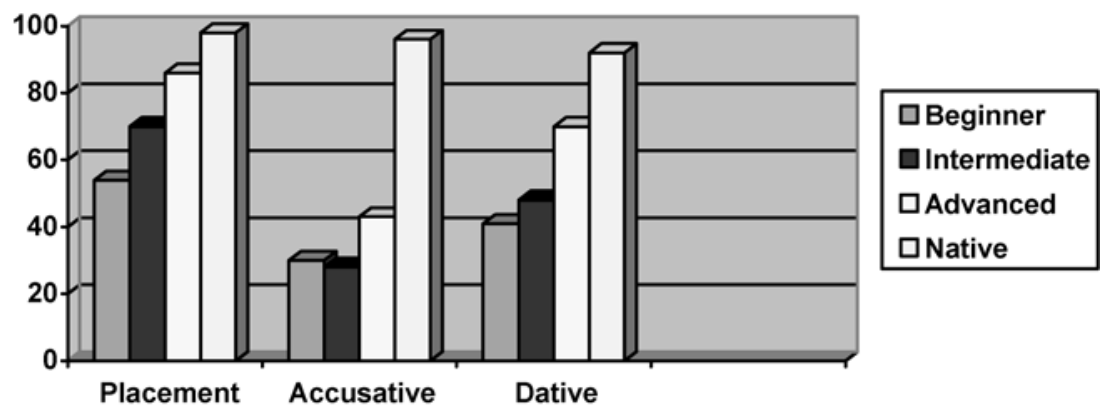

Figure 1 Accuracy rates on ungrammatical items testing for placement, accusative case and dative case among the three experimental groups and Italian natives 


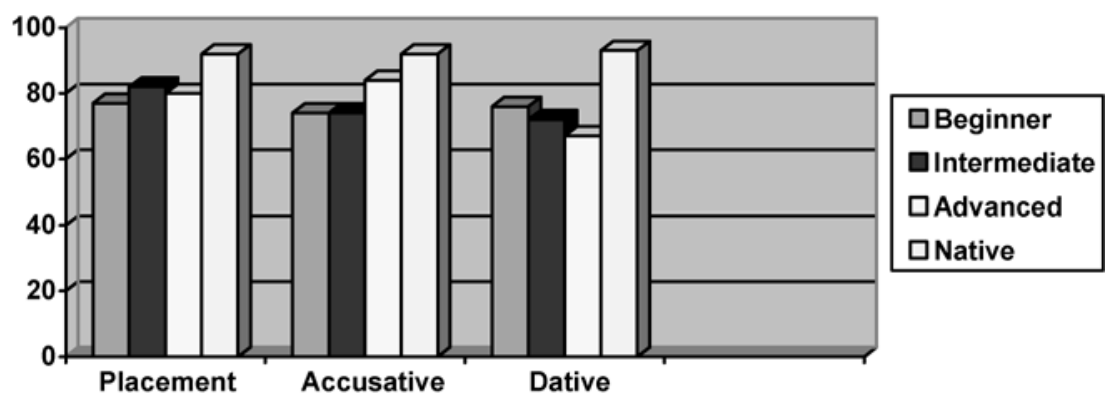

Figure 2 Accuracy rates on grammatical items testing for placement, accusative case and dative case among the three experimental groups and Italian natives

$p<.01$; Accusative: $t_{1}(22)=0.29, p<1 ; t_{2}(18)=3.21, p<.05$; Dative: $\left.t_{1}(22)=0.77, p<1 ; t_{2}(18)=3.73, p<.05\right)$.

Such a gradual and consistent improvement is not noticed with grammatical items. Although they are generally responded to with greater accuracy when compared with their ungrammatical counterparts, learners' performance does not visibly increase with time. As can be seen in Figure 2, changes among the three experimental groups are negligible.

From an acquisition perspective, the relatively high accuracy rates reported with grammatical items could suggest that L2 learners may be aware of the presence of clitics already in early acquisition stages. However, their low performance with ungrammatical items shows that their knowledge is not target-like, and that their false hypotheses about the Italian pronominal system are quite persistent.

A closer look at the data also reveals clear discrepancies in accuracy among the three properties tested. At any proficiency level, sentences featuring incorrectly placed pronouns were judged more accurately than those featuring wrongly-cased pronouns. Differences, in fact, reached statistical significance for each learner group (see Table 6).

In acquisition terms, such results seem to indicate that, although Italian cliticization follows a slow but gradual developmental process, not all properties are acquired at the same rate. The following acquisition pattern regarding the acquisition of Placement and Case can be distinguished in the data:

- Up to 12 months of exposure and formal instruction in Italian (end of the first year), English speakers appear to be aware of the presence of 
Table 6 Effects of manipulation type on judgements of ungrammatical items by the three experimental groups

\begin{tabular}{lll}
\hline Beginner: & & \\
Placement vs. Accusative & $T_{1}(1,11)=14.58, p<.003$ & $* *$ \\
Placement vs. Dative & $T_{2}(1,38)=30.40, p<.001$ & $* * *$ \\
& $T_{1}(1,11)=4.87, p<.05$ & $*$ \\
Intermediate: & $T_{2}(1,38)=10.38, p<.003$ & $* *$ \\
Placement vs. Accusative & $T_{1}(1,11)=31.11, p<.005$ & $* *$ \\
Placement vs. Dative & $T_{2}(1,38)=74.74, p<.001$ & $* * *$ \\
& $T_{1}(1,11)=8.65, p<.005$ & $* *$ \\
Advanced: & $T_{2}(1,38)=14.57, p<.005$ & $* *$ \\
Placement vs. Accusative & $T_{1}(1,11)=36.32, p<.001$ & $* * *$ \\
Placement vs. Dative & $T_{2}(1,38)=93.22, p<.001$ & $* * *$ \\
& $T_{1}(1,11)=4.03, p<.05$ & $*$ \\
\hline
\end{tabular}

Notes: * indicates degree of significance; $T_{1}$ indicates subject-based analysis of variance; $T_{2}$ indicates item-based analysis of variance.

clitics in L2 input, but they are not so sure on how to use them correctly. Despite their uncertainty, however, they seem to have a better understanding of where they should be placed in the structure than with what verb they should be associated.

- At month 18 (end of third semester), learners' knowledge of Italian clitics visibly increases, even though the initial developmental discrepancy still persists. Their multiple placement does not seem to affect L2 learners as much as their morphological variation.

- At month 24 and beyond, English speakers' familiarity with Italian clitics has substantially increased. However, similarly to previous stages, the improvement is not uniform. Again, learners seem to have developed a better understanding of Italian pronominal placement, but they still struggle with clitic case morphology. After two years of instruction, knowledge of placement is almost target-like, whereas case is not.

In sum, the property of Placement develops in a rather consistent manner. The acquisition of Case is much slower, and, after a long period of instruction, does not reach high developmental levels.

\section{Discussion}

The data have highlighted two major issues with regard to the L2 acquisition of Italian clitic properties, namely (1) they are mastered late, and 
(2) they do not follow similar acquisition patterns. Now the following question arises: Are clitic projections activated late because L2 learners are unable to access knowledge of Universal Grammar and, hence, (1) are incapable of mastering properties or structures that are not part of their L1 (the No Access Hypothesis), or (2) because their initial L2 grammars consist of only lexical categories, and the functional structure develops subsequently (the Minimal Trees Hypothesis), or (3) because some operations of Italian cliticization are intrinsically complex, even though UG properties and categories may be available from the start of acquisition (the Full Access Hypothesis)?

The profile of results obtained is consistent with the second and the third of these possibilities. Properties and categories non-existent in the L1 (English in this case) may still be activated by L2 input. As we have seen, beginners judged grammatical items testing for placement at a relatively high accuracy rate $(65 \%)$. This is not a trivial percentage if we consider the multiple placements of Italian clitics and the meagre amount of instruction received. This could be indicative that, already in early stages, L2 learners may be aware of the presence of these pronouns in L2 input. Their poor performance with ungrammatical items, however, suggests that the projections hosting the clitics have not yet developed, and may take some time to be fully activated.

Such an interpretation of the data is corroborated by the fact that the increase in performance from the beginning to the intermediate level is not as visible as the one from the intermediate to the advanced level, suggesting that, once the clitic projections are in place, the development of pronouns is expedited. Additional evidence for a later activation of these projections in Italian interlanguages can be drawn from the inconsistent acquisition patterns of Placement, Accusative and Dative Case. As we have seen, these properties do not develop uniformly showing clear discrepancies, even between the two types of Case. This is consistent with an initial grammar that consists only of lexical categories with functional projections developing later (the Minimal Trees Hypothesis).

On the other hand, the distinct acquisition processes of Placement and Case provides evidence that the development of case-morphology is independent from the development of the syntactic representation. This is consistent with the Missing Surface Inflection Hypothesis (Lardiere, 1998; Prévost and White, 2000), according to which the 
development of morphological affixation is dissociated from syntactic knowledge of formal features. Therefore, the morphological variability should not be attributed to an impairment of the morphosyntactic representation, but it is more an interface problem, reflecting difficulties in accessing or using underlying knowledge. This is also consistent with a modular view of language acquisition according to which linguistic modules develop independently from one another, even though it is their interaction that determines the development of L2 grammars.

\section{Acknowledgements}

The research reported in this article is part of my dissertation and was presented at the 2004 Kentucky Foreign language conference held at the University of Kentucky in April 2004. I would like to thank Ricardo Otheguy, Marcel den Dikken, Edward Bendix and Joseph Davis from the City University of New York for their invaluable comments and suggestions.

\section{References}

Bley-Vroman, R. 1989: The logical problem of second language learning. In Gass, S. and Schachter, J., editors, Linguistic perspective on second language acquisition. Cambridge University Press.

Bruhn-Garavito, J. and Montrul, S. 1996: Verb movement and clitic placement in French and Spanish as a second language. In Proceedings of the 21st Boston University Conference on Language Development Cascadilla Press, 123-34.

Cardinaletti, A. and Starke, M. 1999: The typology of structural deficiency: a case study of three classes of pronouns. In Van Riemsdijk, H., editor, Clitics in the languages of Europe Mouton de Gruyter, 145-233.

Clahsen, H. and Muysken, P. 1996: How adult second language learning differs from child first language development. Behavioral and Brain Sciences 19, 721-33.

Duffield, N. and White, L. 1999: Assessing L2 knowledge of Spanish clitic placement: converging methodologies. Second Language Research 15, $133-60$.

Duffield, N., White, L., Bruhn-Garavito, J., Montrul, S. and Prévost, P. 2002: Clitic placement in L2 French: evidence from sentence matching. Journal of Linguistics 39, 487-525. 
Epstein, S., Flynn, S. and Martohardjono, G. 1996: Second language acquisition: theoretical and experimental issues in contemporary research. Brain and Behavioral Sciences 19, 161-86.

Kim, J.-T. 2000: The initial state of second language syntax: an investigation of L2 wh-movement and null-subjects from the minimalist perspective. Unpublished doctoral dissertation, University of California.

Lardiere, D. 1998: Dissociating syntax from morphology in a divergent endstate grammar. Second Language Research 14, 359-75.

Montrul, S. 1996: The second language acquisition of dative case: from absolute L1 influence to optionality. In Proceedings of the 20th Boston University Conference on Language Development. Cascadilla Press, 506-17.

Prévost, P. and White, L. 2000: Missing surface inflection or impairment in second language acquisition? Evidence from tense and agreement. Second Language Research 16, 103-33.

Schaeffer, J.C. 1997: Direct object scrambling in Dutch and Italian child language. Unpublished doctoral dissertation, University of California.

Sportiche, D. 1996: Clitic constructions. In Rooryck, J. and Zaring, L., editors, Phrase Structure and the Lexicon. Kluwer, 213-87.

Vainikka, A. and Young-Scholten, M. 1994: Direct access to X-theory: evidence from Korean and Turkish adults learning German. In Hoekstra, T. and Schwartz, B., editors, Language Acquisition Studies in Generative Grammar. John Benjamins, 317-68.

— 1996: The early stages in adult L2 syntax: additional evidence from Romance speakers. Second Language Research 12, 140-76.

White, L. 1996: Clitics in L2 French. In Clahsen, H., editor, Generative perspectives on language acquisition. John Benjamins, 335-68. 